\title{
Dosa Yerusalem dalam Yehezkiel 22:1-31: Kajian Biblika dan Implikasi Praktis
}

\section{The Sins of Jerusalem in Ezekiel 22:1-31: Biblical Studies and Practical Implications}

\author{
Gabriel Yobert Rajo ${ }^{1)^{*}}$ \\ ${ }^{1)}$ Gereja Kibaid Jemaat Merauke \\ *Penulis Korespondensi: gabrielyobert.rajo@yahoo.com
}

Received: 1508 2020/ Accepted: 3012 2020/ Published: 31122020

\begin{abstract}
Abstrak
Tujuan dari penulisan artikel ini adalah mengkaji secara biblika dosa Yerusalem Yehezkiel 22:1-31 dan memberikan implikasi praktis bagi masyarakat saat ini. Penelitian ini adalah penelitian kualitatif yang bersifat penelitian kepustakaan dengan menggunakan metode hermeneutik Alkitab. Kesimpulan yang penulis dapatkan sebagai berikut. Pertama, ALLAH ingin menjatuhkan hukuman terhadap kaum Israel di kota Yerusalem akibat dari hutang darah dan perbuatan keji yang mereka lakukan. Kedua, ALLAH menuntun segala perbuatan keji kaum Israel di kota Yerusalem mulai dari pemimpin-pemimpin sampai kepada rakyat biasa yang membuat kota itu banyak hutang darah. Ketiga, ALLAH membinasakan kota Yerusalem akibat dari pemimpin-pemimpin di kota Yerusalem berbuat pelanggaran dan kejahatan yang melanggar ketetapan-ketetapan ALLAH. Implikasi yang dapat diambil adalah: Menjadi teladan dalam memimpin, menjauhkan diri dari dosa yang menajiskan, hidup benar di hadapan Tuhan, dan membangun hubungan yang baik dengan ALLAH.
\end{abstract}

Kata-kata Kunci: Dosa, Hutang Darah, Kaum Israel, Murka, Yerusalem

\begin{abstract}
The purpose of this article is to examine biblically the sin of Jerusalem Ezekiel 22:1-31 and provide practical implications for people today. This research is a qualitative research which is library research using the hermeneutic of the Bible method's. The conclusion is as follows. First, God wants to punish the Israelites in the city of Jerusalem because of their blood debt and their abominable deeds. Second, GOD guided all the heinous deeds of the Israelites in the city of Jerusalem from the leaders to the common people who made the city so much blood owed. Third, God destroyed the city of Jerusalem because the leaders in the city of Jerusalem committed transgressions and crimes that violated GOD's decrees. The implications are: Being an example in leading, keeping away from
\end{abstract}


defiling sins, living righteously before God, and building a good relationship with GOD.

Keywords: Blood Debt, Israelites, Jerusalem, Sin, Wrath.

\section{PENDAHULUAN}

Dosa adalah hal yang dilanggar, yang tidak sesuai dengan perintah atau peraturan yang TUHAN sudah tekankan dalam kehidupan manusia. Dosa merupakan kejahatan yang dengan sengaja dilakukan oleh manusia untuk kepentingan duniawinya, sebab dosa merupakan sesuatu hal yang tidak dapat dipisahkan oleh manusia semenjak Adam dan Hawa berbuat dosa di taman Eden. Setelah kejadian itu manusia terus-menerus berbuat dosa. Bobot kejahatan dosa itu nampak dalam kenyataan yang ada, bahwa dosa itu memperkosa kedaulatan ALLAH dan perintahNya dalam hal kekuasaan, kebaikan, hikmat, keadilan, kesetiaan dan kasih karuniaNya.

Berbicara tentang dosa, penulis ingin membahas masalah yang terjadi terhadap kaum Israel di kota Yerusalem pada saat itu (Yehezkiel 21:20;24), di mana mereka berbuat dosa sehingga membuat ALLAH menjadi murka atas mereka. ALLAH memberikan pesan kepada nabi Yehezkiel untuk memperingatkan dampak dari dosa yang dilakukan kaum Israel di kota Yerusalem pada saat itu. Penulis memilih kitab Yehezkiel karena dalam kitab Yehezkiel ini menceritakan bagaimana masa-masa penderitaan bangsa Israel dan Yehuda pada saat itu ketika mereka ditawan dan ditindas oleh raja Nebukadnezar dari Babilonia serta penglihatan nabi Yehezkiel tentang kehancuran kerajaan Yehuda serta pembuangan bangsa Israel pada masa kehancuran tersebut. Penulis tertarik untuk membahas masalah yang terjadi di dalam kitab Yehezkiel ini adalah ketika bangsa Yehuda dan Israel pada saat itu telah ditawan dan ditindas oleh raja Nebukadnezar, bangsa Yehuda yang berada di bawah pimpinan raja Yoyakim tidak mengandalkan ALLAH sebagai penolong mereka namun mereka malah terus berbuat dosa. Nabi Yeremia mengatakan bahwa pada masa jabatan Yoyakim menjabat sebagai raja Yehuda merupakan pemerintahan yang jahat, karena pada saat itu bangsa Yehuda melakukan penyembahan berhala, ketidakadilan sosial, perampokan, pembunuhan, pemerasan, perzinahan, dan penolakan terhadap perjanjian dengan TUHAN (Yer. 22:1-17; Andrew E. Hill \& Walton, 2013, p. 555)

Dalam nas yang menjadi masalah dalam penulisan ini juga terdapat dosa penyembahan berhala yang dilakukan di kota Yerusalem, Yehezkiel 22:3-4 dijelaskan bahwa kaum Israel membuat berhala yang menajiskan diri mereka sendiri dan dengan berhala-hala itu membuat perbuatan mereka menjadi najis. Mereka juga pada saat itu membuat diri terlihat menjijikan di mata ALLAH bahkan akal dan suara hati mereka najis sehingga di mata ALLAH suatupun tidak ada yang suci (Henry, 2018, 
p. 434). Dosa-dosa yang dilakukan kaum Israel dalam Yehezkiel 22:1-31 membuat mereka mempunyai hutang darah akibat perbuatan mereka yang keji (ayat 1). Dalam nas ini kota Yerusalem adalah kota pertumpahan darah sebab kota ini banyak melakukan hal ketidakadilan, kekejaman dan kenajisan sehingga membuat kehancuran terhadap kota Yerusalem dan pengasingan penduduknya. Akibat dari hutang darah itu ALLAH memberikan pesan kepada kaum Israel yang ada di kota Yerusalem untuk bertobat agar mereka mengerti bahwa ALLAH adalah TUHAN (Tuell, 2009, p. 144). Dalam ayat 1-16 penulis melihat bahwa penyebutan kata "darah" ditulis 7 kali dalam nas ini, hal ini menggambarkan bahwa kaum Israel melakukan dosa pembunuhan yaitu saling membunuh satu sama lain dan mereka melakukan dosa tersebut demi kepentingan pribadi mereka. Bukan hanya pembunuhan dan kenajisan karena penyembahan berhala saja yang mereka lakukan, sebab dalam teks Yehezkiel dari pasal 16-23 kaum Israel juga melakukan pencemaran dan persundalan dan pasal-pasal ini hampir dicap sebagai pornografi karena akibat dari pencemaran dan persundalan yang dilakukan kaum Israel (Gertz dkk., 2017, p. 549). Selain pembunuhan, penyembahan berhala, persundalan dan pencemaran, di dalam pasal 22 kaum Israel di kota Yerusalem juga melakukan dosa seperti tidak taat kepada orang tua, penindasan dan pemerasan, penajisan hari sabat dan ketidakpedulian kepada ALLAH (Henry, 2018, p. 435-436).

Dalam permasalahan yang terjadi di kota Yerusalem akibat dosa-dosa yang mereka lakukan, ALLAH memanggil dan memilih nabi Yehezkiel untuk menjadi penjaga bagi kaum Israel untuk memberitahu atau memperingatkan kaum Israel melalui penglihatan nabi Yehezkiel agar mereka tidak berbuat dosa di tengah-tengah kaum Yehuda di kota Yerusalem dan tetap mengikuti peraturan dan perjanjian yang sudah ALLAH tetapkan bagi mereka. Dalam Yehezkiel 3:17 tertulis bahwa nabi Yehezkiel dipakai ALLAH untuk memperingatkan kaum Israel (Paat, 2016). Peran nabi Yehezkiel dalam memperingatkan kaum Israel sangatlah penting bagi kehidupan kerohanian mereka agar terhindar dari dosa-dosa yang ada di kota Yerusalem pada saat itu, sebab nabi Yehezkiel bertanggung jawab dalam mengajar serta mengaplikasikan berita tentang kesalahan dan penghukuman melalui firman dan tindakan simbolis. Nabi Yehezkiel juga membicarakan tentang transformasi gemilang untuk zaman baru yang ditandai dengan kembalinya kemulian ALLAH di bait-Nya (Gemeran, 2011, p. 354). Itu sebabnya dalam Yehezkiel 22:1-31 dia mengaplikasikan nubuat dari ALLAH tentang kesalahan yang dibuat oleh kaum Israel di kota Yerusalem yang berujung pada pembinasaan oleh api murka ALLAH.

Nas ini jug berbicara tentang siapa-siapa saja yang berbuat dosa sehingga disebut sebagai dosa kota. Jika dilihat dalam Yehezkiel 22:6;26-28 dikatakan bahwa yang melakukan dosa sehingga disebut sebagai dosa kota adalah para pemimpin Israel pada saat itu, dan di ayat 7-12 dan ayat 29 di situ dikatakan bahwa karena dosa penduduk itu sehingga disebut sebagai dosa kota dan akibat dari dosa kota ALLAH menjatuhkan hukuman penghakiman dengan cara pembinasaan. Dan yang menjadi masalahnya adalah apakah dalam dosa kota Yerusalem, ALLAH membinasakan 
mereka semua ataukah ALLAH hanya membinasakan sebagian orang saja yang berada di kota Yerusalem? Karena ada beberapa penafsir yang menafsirkan secara berbeda tentang tafsiran mengenai pembinasaan mereka. Dalam tafsiran Matthew Henry dikatakan bahwa: kaum Israel seperti sanga yang dipisahakan dari logam yang baik untuk dimurnikan, jadi artinya bahwa orang yang berdosa akan dihancurkan tetapi orang yang bertobat akan diubahkan dan dibuat layak untuk kelepasan (Henry, 2018, p. 437). Jadi menurut tafsiran Matthew Henry bahwa tidak semua dibinasakan dalam kota Yerusalem karena ALLAH akan membuat kelepasan terhadap orang yang bertobat.

Sedangkan menurut Steven Tueel dikatakan bahwa: pembinasaan yang dilakukan ALLAH bukanlah tentang pemurnian tetapi kehancuran karena ALLAH menyatakan Aku akan meniup kamu dengan murka-Ku yang menyala-nyala dan kami akan dilebur di dalam Dia sehingga seperti perak yang meleleh begitu pula kamu akan meleleh di dalam dirinya (Tuell, 2009, p. 146). Jadi menurut tafsiran Steven Tuell bahwa ALLAH akan membinasakan kaum Israel dengan murka-Nya sehingga mereka akan meleleh seperti perak dan penghakiman ALLAH bukan soal pemurnian tetapi soal kehancuran sehingga semua kaum Israel akan dibinasakan. Namun ALLAH tidak pernah melupakan janji kepada Daud yaitu tentang pembuatan rumah kediaman ALLAH serta keturunan raja-raja di mana ALLAH menjanjikan keturunannya Daud menjadi raja selama-lamanya. Janji ini juga merupakan pengharapan akan seorang Mesias yang digenapi dalam Perjanjian Baru. Juga melalui keturunan Daud ALLAH akan menyalurkan keselamatan-Nya atas bangsa Israel (2 Sam. 7:10,11) (A. Simanjuntak, 2000, p. 481) itu sebabnya penulisan Matthew Henry berpegang pada janji ALLAH kepada Daud.

\section{TEORI}

Kajian Biblika adalah merupakan penelitian yang memiliki satu variable yang berupa konsep, implikasi teologi dan praktis. Dalam metode kajian Biblika mempunyai tujuan yaitu untuk menjelaskan kebenaran melaui metode penafsiran, bentuk dan struktur nas serta menjelaskan implikasi teologis dan praktis (Wijaya, 2016, p. 42). Dosa-dosa Yerusalem merupakan dosa yang pantas dihukum karena keduharkaan yang dilakukan bangsa Israel di Yerusalem sehinga membuat mereka terlihat najis seperti perempuan yang menjadi najis selama haid (Tarigan, 2020). Konsep dosa dalam nas ini adalah berhubungan dengan bagaimana perilaku yang dilakukan oleh pemimpin-pemimpin Israel pada saat itu yang hidupnya jauh dari perintah ALLAH sehingga mereka melakukan kesalahan yang mengakibatkan orangorang Israel juga mengikuti pemimpin mereka. Kemudian konsep ALLAH mengenai dosa Yerusalem merupakan suatu perbuatan hutang darah dengan menyembah berhala-berhala sehingga membuat mereka menjadi najis di hadapan ALLAH sehingga dari dosa yang mereka lakukan membuat ALLAH ingin membinasakan bangsa Israel. 


\section{METODE}

Metode penelitian yang digunakan adalah metode penelitian kualitatif yaitu metode penelitian kepustakaan (Library Research) dengan menggunakan metode hermeneutik yang berhubungan dengan tema penulisan ini dengan menggunakan Alkitab dalam berbagai cetakan, kamus, tafsiran dan buku-buku serta berbagai literatur dan tulisan online yang berhubungan dengan kitab Yehezkiel. Metode penafsiran hermeneutik pada umumnya berupa analisis bentuk/genre, struktur dan teks. Struktur pembahasan didasarkan pada struktur nas dan didasarkan pendekatan penafsiran sesuai dengan genre nas (Wijaya, 2016, p. 40). Hermeneutik mempunyai arti menyampaikan, menjelaskan dan menerjemahkan (Sutanto, 2007, p. 3). Dalam pembahasan kitab Yehezkiel 22:1-31, penulis memakai penafsiran eksposisi karena dalam penafsiran di dalam Yehezkiel 22:1-31 berfokus pada pengertian suatu bagian teks. Dalam pembahasan ini juga penulis berfokus pada penafsiran nubuat karena dalam penafsiran nubuat sering menimbulkan perdebatan dalam teks (Sutanto, 2007, p. 395). Hermeneutik Alkitab adalah metode penafsiran yang bertujuan untuk menemukan maksud yang ingin disampaikan oleh penulis Alkitab (Sutanto, 2007, p. 8).

\section{HASIL DAN PEMBAHASAN}

\section{Kajian Biblika Yehezkiel 22:1-31}

\section{TUHAN Ingin Menjatuhkan Hukuman Atas Kota Yerusalem (1-2)}

Dalam nas ini kota Yerusalem dan penduduknya telah berbuat dosa terhadap ALLAH dan mereka berdosa karena menumpahkan darah (Walvoord, 2003, p. 217). Dalam hal ini ALLAH ingin menjatuhkan hukuman kepada kaum Israel akibat dari dosa yang mereka lakukan sehingga ALLAH memberikan pesan kepada nabi Yehezkiel untuk memberitahukan kepada kaum Israel bahwa ALLAH akan menjatuhkan hukuman atas mereka akibat perbuatan mereka yang keji. Pada pasal sebelumnya ALLAH sudah memberi pesan kepada Yehezkiel tentang nubuat penghukuman yang akan terjadi jika kaum Israel masih saja berbuat kejahatan, namun nubuatan itu diindahkan oleh mereka sehingga ALLAH menegur mereka (20:46). Maksud ALLAH menegur adalah karena mereka masih mengikuti cara hidup nenek moyang mereka, di mana mereka hidup dengan berzinah dan mengikuti dewa-dewa yang menjijikan (20:31-32). Karena ALLAH sudah menegur mereka melaui nubuatan yang diberikan kepada Yehezkiel namun mereka masih berbuat kejahatan dosa maka ALLAH menjatuhkan hukuman atas mereka akibat dari hutang darah yang mereka perbuat. 


\section{Dosa-Dosa yang Dilakukan di Kota Yerusalem (3-12)}

Dalam bagian ini diayat 3-12 adalah penjabaran tentang dosa-dosa yang dilakukan di kota Yerusalem. Mereka melakukan dosa terhadap sesama mereka dan juga melakukan dosa terhadap ALLAH. Ayat 3-5 adalah sebuat dakwaan umum tentang pertumpahan darah dan berhala-berhala di Yerusalem itu sebabnya ALLAH mempermalukan mereka kepada semua bangsa baik yang dekat maupun yang jauh. Dakwaan ini diberi julukan dengan nama najis dan keributan besar sebab kota Yerusalem terkenal dengan kedua julukan ini akibat dari dosa-dosa yang mereka perbuat. Ayat 6-12 merupakan sebuag dakwaan tentang kejahatan kota Yerusalem dalam serangkaian pelanggaran budaya, seksual dan sosial. Dakwaan ini merupakan gambaran dari kemunduran yang progresif dalam jalinan kehidupan komunitas. Melemahnya komunitas dimulai dengan penyalahgunaan kekuasaan oleh pemerintah Yerusalem yang tidak hanya merusak unit sosial yang paling mendasar yaitu keluarga namun juga membayahkan pinggiran masyarakat Yerusalem. Selain itu juga tidak wanita di Yerusalem yang aman dari serangan seksual bahkan keluarga dekatpun ikut melakukan hal tersebut. Kekerasan ini tidak dapat diatasi sebab keinginan pemimpin Yerusalem untuk berkuasa, sehingga tidak menjadikan tetangga yang bisa diandalkan dalam komunitas internasional (Odell, 2005. p. 282-283). Itu sebabnya masyarakat dan pemimpin di kota Yerusalem banyak membuat hal-hal yang tidak sesuai dengan peraturan-peraturan yang ALLAH telah tetapkan kepada mereka.

Manusia tidak pernah luput dari namanya dosa, karena dosa sudah ada sejak penciptaan manusia yang pertama dan akibat dari dosa tersebut timbul adanya penghukuman. Hukuman atas dosa merupakan sebuah tindakan ALLAH terhadap dosa. Maksud utama dari penghukuman dosa ini adalah untuk memperbaiki orang yang dihukum karena dosa. Bukan juga untuk menakut-nakuti orang untuk jangan berbuat dosa namun maksud utama atas hukuman dosa adalah supaya kesucian ALLAH dibenarkan (Brill, 2015, p. 305). Jadi dalam ayat 3-12 ini terdapat beberapa dosa yang dilakukan kaum Israel yang berasal dan penumpahan darah maupun dari kekerasan-kekerasan sosial. Yehezkiel telah menyadari dosa-dosa yang mereka lakukan sehingga Yehezkiel memberikan dakwaan kepada mereka untuk meyakinkan bahwa mereka bersalah akibat dari kejahatan-kejahatan yang mereka lakukan. Kesalahan ini yang membuat ALLAH ingin penuntut mereka dan menjatuhkan hukuman atas mereka. Dosa dan kesalahan yang mereka lakukan semuanya berakhir dengan mencurahkan darah. Itu sebabnya ALLAH ingin menjatuhkan hukuman atas mereka agar ALLAH dibenarkan dalam semua kehancuran yang didatangkan-Nya atas Yerusalem.

\section{Putusan ALLAH Untuk Menjatuhkan Hukum Atas Yerusalem (13-16)}

Dalam hal ini setelah ALLAH mendakwah setiap kesalahan-kesalahan yang dilakukan kaum Israel, ALLAH membuat putusan akan kesalahan dan kejahatan yang mereka lakukan di kota Yerusalem. Dari ayat 13-16 adalah sebuah putusan-putusan karena kaum Israel sudah melupakan ALLAH dan melanggar segala aturan yang 
sudah ALLAH tetapkan kepada mereka. ALLAH ingin menuntut mereka atas setiap pertumpahan darah yang mereka lakukan sebab setiap dosa dan kesalahan yang mereka lakukan di tengah-tengah kota pasti akan berujung dengan pencurahan darah atau pembunuhan itu sebabnya ALLAH akan penuntun mereka dan juga ALLAH akan membuat mereka najis di hadapan seluruh bangsa-bangsa atas kesalahan dan dosa yang telah mereka perbuat.

Aku bertepuk tangan mengenai keuntunganmu yang haram dan mengenai darah yang dicurahkan. Dalam hal ini ALLAH tidak berkenan atas mereka kaum Israel karena mereka melakukan kejahatan tentang keuntungan yang haram dan mencurahkan darah. Di ayat ini ALLAH memperlihatkan tindakan karena kejahatan yang mereka

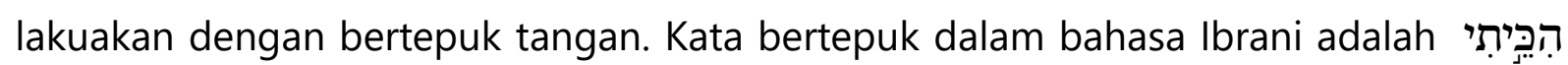
(hikketi, Yeh. 22:13, WTT) kata kerja perfek orang pertama tunggal, dari kata dasar נָכָה (nakah) (Bibleworks Version 7). Arti dari kata ini adalah memukul, memukul dengan keras, supaya dia mati, membunuh, mengalahkan, ditimpahkan binasa dan menjulurkan (Achenbach, 2012, p. 214-215). Jadi arti dari kata "ALLAH bertepuk" tangan adalah bahwa ALLAH akan memukul dengan keras, mengalahkan dan ditimpahkan binasa atau membunuh kaum Israel dengan tangan-Nya karena dalam bahasa aslinya di situ memakai awalan kata perintah dan memakai akhiran kata "saya" sehingga ALLAH memerintahkan nabi Yehezkiel untuk memberitahukan kepada kaum Israel bahwa ALLAH akan membinasakan, mengalahkan atau membunuh kaum Israel dengan tangan-Nya akibat dari pelanggaran dan kejahatan yang mereka lakukan di tengah kota Yerusalem. ALLAH benar-benar menunjukan murka-Nya terhadap cara hidup umat-Nya yang jahat sehingga ALLAH bertepuk tangan atas mereka agar mereka jangan sampai berkata mereka tidak diperingatkan dengan adil (Henry, 2018, p. 438).

Apakah hatimu akan tetap teguh dan merasa tangan merasa kuat pada masa Aku bertindak terhadap engkau? Ini merupakan pertanyaan retoris yang disampaikan kepada kaum Israel sebelum penghakiman yang akan dilakukan oleh ALLAH, di mana ALLAH mempertanyakan keberanian mereka untuk menghadapi penghakiman dan tangan mereka akan terkulai (7:17) akibat dari penghakiman yang akan ALLAH lakukan kepada mereka (Wevers, 1982, p. 130). ALLAH akan memberi kepastian bahwa penghancuran akan pasti diterima oleh mereka sebab ALLAH akan setia dengan janji-janji-Nya dan ALLAH tidak akan menyesal sebab Dia bukanlah manusia (Henry, 2018, p. 438). Kaum Israel tidak akan bisa mengindar dari penghakiman yang sudah ALLAH janjikan kepada mereka walaupun mereka punya keberanian dan mempunyai tangan yang kuat teteapi mereka bukanlah tandingan buat ALLAH karena yang kaum Israel hadapi ini adalah ALLAH yang hidup yang mempunyai kuasa.

Aku akan menyerakkan engkau di antara bangsa-bangsa dan menghamburkan engkau ke semua negeri dan Aku akan mengikis kenajisanmu dari padamu. Kota Yerusalem melakukan hal yang ceroboh yaitu menentang kanon hukum, baik hukum milik mereka maupun milik bangsa-bangsa lain sehingga ALLAH mencemarkan 
mereka di mata bangsa-bangsa lain (Odell, 2005, p. 286). ALLAH membiarkan kaum Israel untuk mengikuti ajaran-ajaran dari bangsa-bangsa lain serta mempelajari perbuatan-perbuatan mereka. Akibat dari ALLAH membiarkan mereka keluar dari tanah mereka sendiri adalah mereka menjadi disiksa dan dihina oleh orang-orang asing. ALLAH membuat menghamburkan mereka ke semua negeri agar mereka dapat dimurnikan dari kenajisan mereka (Henry, 2018, p. 439). Jadi dari penjelasan di atas bahwa ALLAH ingin membubarkan mereka yang najis dari kota Yerusalem sehingga mereka merasakan penyiksaan dan hinaan akibat dari kenajisan hidup yang mereka miliki.

Engkau akan dinajiskan di hadapan bangsa-bangsa karena kesalahanmu sendiri. Akibat dari kenajisan dari kaum Israel sehingga ALLAH membuat mereka najis dihadapan semua bangsa agar mereka tau bahwa ALLAH telah menolak mereka dan membuang mereka. Mereka yang melakukan kejahatan hawa nafsu akan mendapatkan perlakukan hawa nafsu juga dari bangsa-bangsa lain dan juga mereka yang menjadi tuan atas dirinya sendiri tidak akan mendapatkan kebaikan dan kebahagiaan dari bangsa-bangsa lain (Henry, 2018, p. 440). Akibat dari kenajisan yang mereka lakukan dan mereka diperhadapkan kepada bangsa-bangsa lain, mereka akhirnya belajar sesuatu tentang ALLAH yang mereka lupakan (Tuell, 2009, p. 145). Dari penjelasan di atas bahwa ALLAH ingin mengingatkan kepada kaum Israel bahwa ALLAH yang mereka lupakan adalah ALLAH yang hidup dan mahakuasa sehingga mereka akan belajar dari kesalahan mereka dengan cara ALLAH akan membuat mereka merasakan dosa yang mereka lakukan sehingga ALLAH menyerahkan mereka kepada bangsa-bangsa lain dengan kenajisan dosa yang mereka miliki.

\section{Gambaran Hukuman Atas Kota Yerusalem (17-22)}

Dalam nas ini merupakan sebuah gambaran hukuman yang akan terjadi kepada kaum Israel atas kejahatan dan dosa yang mereka perbuat. ALLAH menggambarkan murka-Nya terhadap kaum Israel karena mereka tidak taat kepada ketetapanketetapan yang sudah ALLAH berikan kepada mereka. ALLAH akan menyulutkan amarahnya dalam berbagai gambaran kepada kaum Israel mulai dari Api yang akan meleburkan hingga mereka disamakan seperti sanga. ALLAH akan mengumpulkan mereka semua dan membuat mereka seperti sanga yang dileburkan di tengahtengah kota Yerusalem. Kaum Israel di sini tidak bisa bertindak atau melawan amarah ALLAH dan tidak ada seorang pun yang dapat menolong mereka dari amarah ALLAH sehingga mereka akan dilahap oleh api murka ALLAH.

Kaum Israel sudah menjadi sanga. Pada awalnya sebelum kaum Israel melakukan dosa dan mengalami kemerosotan akhlak, mereka digambarkan seperti kepala yang dari emas namun karena perpecahan sebuah kerajaan sehingga mereka digambarkan lagi sebagai lengan perak. Namun akibat dari pelanggaran dan dosa sehingga kaum Israel merosot menjadi sebuah logam yang tidak berharga dan mereka semua digambarkan seperti tembaga, timah putih, besi dan timah hitam. 
Gambaran ini menggolongkan jenis orang berdosa yang ada di kota Yerusalem. Yang pertama tembaga, melambangkan kelancangan tak kenal malu sebagian orang dalam kejahatan mereka. Yang kedua timah besi, melambangkan perbuatan kesalehan yang munafik yang mereka gunakan untuk menutupi kesalahan mereka. Yang ketiga besi, melambangkan kecondongan hati yang kejam dalam diri sebagian orang dan kesukaan mereka akan perang karena itu sesuai dengan watak zaman besi. Yang keempat timah hitam, melambangkan kebebalan, kedunguan, dan kebodohan. Namun kemerosotan kaum Israel tentang keempat gambaran ini belum yang terburuk, sebab keempat gambaran tentang logam-logam ini masih ada kegunaannya akan tetapi kemerosotan yang sesungguhnya dari kaum Israel adalah bahwa ALLAH telah mamandang kaum Israel seperti sanga perak (Henry, 2018, p. 441). Sanga dalam bahasa Ibrani artinya adalah לְסוּג (lesug; Yeh. 22:18, WTT) kata benda tunggal maskulin dari kata dasar סִיג (sig) artinya adalah terak, kerak, dan tidak murni (Achenbach, 2012, p. 225). Jadi maksudnya "sanga" adalah sebuah ampas leburan dari sebuah logam sehingga sudah tidak murni lagi.

Dalam hal ini adalah mengambarkan kemurkaan dan amarah ALLAH kepada kaum Israel. ALLAH telah menganggap kaum Israel seperti sanga perak sebab mereka mereka sudah menjadi sampah dan tidak yang bernilai di mata ALLAH (Odell, 2005, p. 287). Itu sebabnya kaum Israel digambarkan seperti sisi logam yang tidak akan menghasilkan perak walaupun seberapa panas api (Tuell, 2009, p. 146). "Aku akan mengumpulkan kamu di tengah-tengah Yerusalem" (ay. 19). Artinya dalam hal ini bahwa mereka akan dikumpulkan ALLAH seperti berkumpulnya berbagai logam dalam peleburan atau tungku untuk dileburkan dan dipisahkan dari sanga yang melekat. Kaum Israel berpikir bahwa mereka dikumpul ALLAH di tengah-tengah untuk mendapatkan sebuah keamaan dan menjadi tempat perlindungan padahal mereka dikelilingi pasukan musuh. Namun maksud ALLAH mengumpulkan mereka di tengah-tengah kota adalah untuk meleburkan mereka dengan api ALLAH yang menyala dengan ganas dan kuat (ay. 20-21; Henry, 2018, p. 442).

Sehingga dalam hal ini kaum Israel dikumpulkan bukan maksud untuk pemurnian, tetapi kehancuran sebab ALLAH akan meniup mereka dengan murka-Nya yang menyala-nyala dan mereka akan dilebur seperti perak yang meleleh (ay. 21-22; Tuell, 2009, p. 146). Dengan kemurkaan ALLAH, kaum Israel tidak mempunyai kekuatan lagi dan mereka akan kehilangan semua bentuk sehingga mereka tidak dapat bertahan di hadapan murka ALLAH. Semua kaum Israel yang berdosa akan dilebur dan bercampur bersama tempat luluhan yang sama seperti halnya tembaga dan timah hitam dalam peleburan yang sama. Setelah ALLAH meleburkan mereka ALLAH akan meninggalkan mereka dan membiarkan mereka dalam peleburan seperti orang membuang sanga ke dalam peleburan untuk dilahap api (Henry, 2018, p. 443). Jadi dalam penjelasan di atas bahwa kaum Israel digambarkan sebagai kotoran sebuah logam atau sampah yang dileburkan dengan api murka dan amarah ALLAH dan tidak murni lagi sehingga ALLAH tidak memperdulikan mereka dan kaum Israel akan seperti perak yang meleleh dan tidak murni lagi. Namun dalam kehancuran 
kaum Israel di kota Yerusalem ALLAH telah membuat janji-janji kepada mereka bahwa ALLAH akan membangun kembali kota dari reruntuhan yang telah terjadi (Yeh. 36:33). ALLAH melakukan memberikan janji kepada untuk memisahkan mereka dari orang-orang berdosa dan memberikan mereka penghiburan (Henry, 2018, p. 699).

\section{Tuduhan Kejahatan Atas Para Nabi, Imam-Imam dan Pemuka-Pemuka di Yerusalem (23-28)}

Dalam hal ini nabi Yehezkiel berbicara tentang bagaimana kejahatan-kejahatan yang dilakukan nabi, imam-imam dan pemuka-pemuka Israel yang membuat kota Yerusalem menjadi hancur. Mereka sebagai pemimpin di dalam kota Yerusalem seharusnya memberikan contoh yang baik kepada masyarakatnya, namun mereka juga yang berbuat pelanggaran dan dosa. Mereka membuat sengsara rakyat Yerusalem dengan kekuasaan yang mereka miliki mulai dari merampas dan mengambil harta benda milik mereka. Pemimpin-pemimpin Israel juga melanggar ketetapan-ketetapan hukum taurat, menajiskan hal-hal yang kudus dan menajiskan hari Sabat mereka juga membunuh rakyatnya untuk kepuasan mereka sendiri serta mereka berbohong tentang firman TUHAN ALLAH. Kejahatan dan pelanggaran yang dilakukan pemimpin Israel inilah yang diikuti oleh kaum Israel di kota Yerusalem sehingga membuat kehidupan mereka menjadi salah dari ketetapan-ketetapan yang ALLAH sudah tetapkan.

Engkau adalah tanah yang tidak menerima hujan, tidak mendapatkan air pada masa kegeraman (ay. 24). Ini adalah salah satu penghakiman ALLAH pada hari kemurkaan-Nya atas kota Yerusalem di mana ALLAH menahan hujan dari mereka (Yer. 14:4). Gambaran tentang "tidak menerima air hujan" ialah bahwa kaum Israel tidak akan menerima petunjuk-petunjuk dari nabi dalam masa kegeraman ALLAH, dan juga tetang "tidak mendapat air" maksudnya ialah bahwa kaum Israel tidak dapat membersihkan diri mereka akibat kenajisan yang mereka perbuat, ibarat seperti musim kering yang tidak mendapatkan air, begitu juga dengan kaum Israel yang bertambah kenajisannya karena tidak bisa dibersihkan lagi di masa kegeraman ALLAH (Henry, 2018, p. 444). Pada masa kegeraman ALLAH kaum Israel tidak akan mendapatkan petunjuk-petunjuk dari ALLAH melalui nabi-nabi dan mereka tidak akan mendapatkan penghiburan dari, karena ALLAH akan menghakimi mereka di masa kegeraman itu.

Pemimpin-pemimpinnya seperti singa yang mengaum yang menerkam mangsanya (ay. 25). Pemimpin-pemimpin Israel digambarkan seperti seekor singa yang mengaum dan merobek mangsanya. Gambaran tentang singa ini juga terdapat pada pasal 19:3. Pemimpin-pemimpin Israel juga dikatakan bahwa mereka merampas harta benda masyarakat (19:7) dan melahap orang-orang (19:8; Tuell, 2009, p. 146). Pemimpin-pemimpin dalam terjemahan NAS adalah prophets yang artinya nabi-nabi. Jadi nabi-nabi dalam kota Yerusalem seperti singa yang mengaum yang mengoyak mangsa untuk mengambil harta dan benda-benda berharga orang lain serta mereka 
membuat banyak janda di tengah-tengah kota. Dikatakan juga dalam terjemahan NAS There is a conspiracy of her prophets midst maksudnya adalah bahwa para nabinabi bersekongkol untuk melakukan kejahatan itu di tengah-tengah kota. Mereka juga bersekongkol dengan para pembunuh dan penindas untuk membantu mereka dalam rencana kejahatan mereka agar mereka bisa mendapat keuntungan dari kejahatan yang mereka lakukan. Kejahatan yang mereka lakukan yang pertama adalah "manusia ditelan mereka" maksudnya adalah mereka membantu pertumpahan darah kepada orang-orang yang tidak berdosa sehingga membuat banyak membuat orang menjadi janda akibat dari kejahatan yang mereka lakukan. Yang kedua adalah harta benda dan barang-barang berharga dirampas oleh mereka atau disita dan mereka merampas harta-harta milik para janda (Mat. 23:14; Henry, 2018, p. 445-446). Jadi akibat dari setiap kejahatan yang dilakukan para pemimpin Israel atau nabi-nabi membuat ALLAH tidak menurunkan hujan atas mereka dan juga tidak memberikan mereka air sehingga mereka menjadi kekeringan dimasa kegeraman ALLAH serta akibat dari kejahatan mereka menumpahkan darah orang yang tidak berdosa dan merampas harta benda dan barang beharga sehingga membuat banyak orang menjadi janda di tengah-tengah kota Yerusalem.

Imam-imamnya memperkosa hukum Taurat-Ku dan menajiskan hal-hal yang kudus bagi-Ku. Para imam-imam telah memutarbalikkan setiap aspek dari panggilan mereka sebagai imam sehingga itu membuat ALLAH dinajiskan (Odell, 2005, p. 290). Para Imam tidak membedakan antara yang suci dengan yang umum dan mereka mengajarkan bahwa tidak ada perbedaan antara yang najis dengan yang kudus sehingga para imam mencampur yang suci dengan yang umum (Tuell, 2009, p. 146147). Para imam juga melanggar hukum ALLAH yang seharusnya mereka taati dan mereka ajarkan kepada orang lain tentang hukum ALLAH. Para imam juga secara terang-terangan melakukan penghinaan terhadap hukum ALLAH. Mereka menajiskan hal-hal yang kudus yang seharusnya tugas seorang imam untuk menjaga hal-hal yang kudus namun mereka sendirilah yang menajiskan hal-hal kudus tersebut seperti makan persembahan-persembahan kudus. Para nabi menutup mata terhadap harihari sabat ALLAH, di mana mereka tidak mempedulikan hari sabat karena mereka mengganggap bahwa hari sabat sama halnya dengan hari-hari lain. Mereka tidak peduli apakah ada orang yang memelihara hari sabat atau tidak dan juga meraka tidak peduli apakah orang mau bekerja disaat hari sabat atau tidak. Para imam sama sekali tidak memperdulikan kaum Israel tentang pengajaran tentang hari Sabat karena mereka juga tidak menghormati hari Sabat ALLAH. Dari semua hal yang para imam lakukan itu secara tidak langsung mereka menajiskan ALLAH, karena mereka telah menyepelekan kuasa ALLAH, meremehkan kebaikan-Nya, dan menghina kedudusannya (Henry, 2018, p. 446-448). Imam-imam yang seharusnya menjadi contoh bagi kaum Israel dalam hal rohani, malah melakuakan pelanggaran rohani yang bertentangan dengan ajaran dan hukum ALLAH. Para imam di kota Yerusalem malah membuat setiap hal yang kudus menjadi najis dan tidak memperdulikan kesalahan mereka itu benar atau salah dan karena pelanggaran yang mereka buat 
mereka menajiskan ALLAH yang telah membuat semua peraturan dan hukum ALLAH (Zef. 3:4).

Kata pemuka-pemuka ini dalam bahasa Ibrani adalah שְְָׁריה (sareah; Yeh. 22:27, WTT) kata benda jamak maskulin orang ketiga tunggal feminism dari kata dasar שַׁ (sar) yang artinya adalah pemimpin, kepala, pengawas, panglima, dan pemuka; pemerintah (Achenbach, 2012, p. 330). Jadi yang dimaksud pemuka-pemuka di sini ialah para pemimpin, kepala, pengawas, dan panglima yang berada di bagian pemerintahan. Dalam ayat ini para pemuka digambarkan seperti serigala yang menerkam mangsanya dalam kehausan akan darah artinya adalah para pemuka di kota Yerusalem yang seharusnya melindungi hak-hak bagi kaum Israel malah menjadi pemangsa dan merampas tuduhan mereka (Tuell, 2009, 147). Mereka juga menumpahkan darah untuk keuntungan yang tidak jujur untuk kepentingan kekuasaan mereka (Odell, 2005, p. 290). Apa yang dilakukan pemuka-pemuka di Yerusalem adalah untuk memuaskan keangkuhan mereka sendiri agar mereka ditakuti oleh orang-orang di Yerusalem. Kemudian juga mereka akan membinasakan orang-orang yang tidak mengikuti kemauan para pemuka-pemuka dan yang tidak tunduk kepada segala yang mereka pemerintahkan. Mereka juga sangat serakah karena tujuannya untuk mencari keuntungan mereka sendiri yang haram dengan cara menghancurkan dan menindas rakyat kecil yang di bawah (Henry, 2018, p. 448). Para pemuka atau pemimpin yang berada dipemerintahan kota Yerusalem yang seharusnya sebagai penengah atas jabatan kekuasaan yang mereka miliki untuk menangani sertiap persoalan masyarakat malah melanggar hukum taurat dan melakukan penglanggran serta kejahatan. Mereka melakukan itu semua untuk kepentingan mereka sendiri dan juga untuk kekuasaanyang mereka miliki.

Dan nabi-nabinya mengoles dengan kapur dengan melihat penglihatan yang menipu dan memberi tenungan bohong bagi mereka. Para nabi membohongi kaum Israel dengan penglihatan yang menipu kaum Israel. Mereka juga memberi tenungan atau ramalan yang tidak benar. Dalam hal ini para nabi dan pemimpin bekerja sama untuk menipu kaum Israel. Para nabi memberikan pengajaran yang salah kepada kaum Israel dengan dasar dalam nama ALLAH, bahwa setiap perbuatan yang dilakukan pemimpin-pemimpin Israel adalah benar dan tidak salah, jadi menurut para nabi, apa yang dilakukan pemimpin-pemimpin dalam hal pertumpahan, pemerasan dan penindasan adalah hal yang benar. Dalam pengajaran yang dilakuakan, mereka berlagak seperti seorang penglihat tetapi mereka berbohong atas penglihatan dan juga berpura-berpura sebagai penenung atau peramal padahal apa yang mereka ramalkan itu adalah dusta atau bohong. Para nabi juga seolah-olah memberi jaminan bahwa setiap penglihatan dan ramalan yang mereka sampaikan itu berasal dari surga atau dari ALLAH mereka berkata beginilah firman TUHAN ALLAH padahal ALLAH tidak berfirman demikian (Henry, 2018, p. 448, 449). Para nabi adalah pembohong sehingga tipuan yang dilakukan para nabi telah menyebabkan Yerusalem menuju kehancuran (Zef. 3; Tuell, 2009, p. 148). Para nabi ini melakukan dusta yang membawa-bawa nama ALLAH, mereka berkata seolah-olah itu berasal dari ALLAH 
dan ini adalah sebuah kejahatan yang mengerikan, sebab ALLAH tidak pernah berfirman kepada mereka seperti itu. Mereka melakukan hal ini untuk melindungi setiap pelanggaran dan dosa yang dilakukan pemimpin pemerintahan kota Yerusalem dari kaum Israel sehingga para pemimpin yang berada di Yerusalem dapat melakukan kejahatan dan pelanggaran yang mereka lakukan kepada kaum Israel.

\section{Dampak Dari Kesalahan Pemimpin-Pemimpin Israel (29-31)}

Kejahatan dan pelanggaran yang dilakukan mulai dari nabi-nabi, imam-iman dan pemuka-pemuka yang ada di kota Yerusalem memiliki dampak kepada masyarakat atau kaum Israel di Yerusalem di mana membuat mereka juga berbuat kejahatan dan melakukan dosa-dosa sehingga membuat kota Yerusalem menuju sebuah kehancuran. Dan juga ALLAH akan mencurahkan geram-Nya dan membinasakan mereka akibat dari pelanggaran yang dilakukan pemimpin-pemimpin Israel dan juga kaum Israel di kota Yerusalem. Dari semua orang yang ada di kota Yerusalem, semuanya melakukan dosa dan pelanggran dan tidak seorang pun yang hidup benar dihadapan ALLAH.

Penduduk negeri melakukan pemerasan dan perampasan, menindas orang sengsara dan miskin dan mereka melakukan pemerasan terhadap orang asing. Orangorang di kota Yerusalem saling berbuat kejahatan kejahatan satu sama lain, di mana orang kaya menindas yang miskin, seorang tuan menindas hambanya, tuan tanah menindas penyewanya bahkan seorang ayah menindas anaknya sendiri dan juga para penjual berusaha saling menindas satu sama lain. Inilah yang dinamakan dengan dosa kota atau bangsa (Yes. 3:50) karena seluruh orang yang ada di dalam kota Yerusalem melakukan dosa mulai dari pemimpin-pemimpinnya sampai kepada penduduk-penduduknya. Dosa yang mereka lakukan bertambah kesahalannya ketika mereka menindas orang sengsara dan miskin padahal seharusnya mereka memberikan kepada orang miskin dan juga orang yang sengsara selain itu juga mereka menindas orang-orang asing dan merampas haknya padahal mereka seharusnya memberi mereka keadilan dan kebaikan (Henry, 2018, p. 449-450). Apa yang dilakukan adalah sesuatu hal yang bertentangan dengan hukum, namun mereka tetap melakukan hal itu. Ini adalah sebuah dampak yang dilakukan pemimpinpemimpin Israel bahwa penduduk di kota tidak ada yang menaati hukum yang ada karena mereka melihat pemimpin-pemimpin mereka juga yang melanggar hukum tersebut.

Aku mencari di tengah-tengah mereka seorang yang hendak mendirikan tembok atau yang mempertahankan negeri itu dihadapan-Ku. Pada awalnya ALLAH sebenarnya tidak ingin memberi penghakiman kepada kota Yerusalem sebab sebelumnya ALLAH mencari seseorang di Yerusalem yang akan berdiri melawan semua penindasan dan kenajisan pemimpin-pemimpin Israel namun ALLAH tidak mendapatkannya (Tuell, 2009, p. 148). Tidak ada yang tampil sebagai pengantara. Semua pemimpin-pemimpin di kota Yerusalem berbuat dosa. Akibat dari dosa yang lakukan mereka menciptakan celah pada pagar pelindungan yang ada di sekitar umat 
sehingga hal-hal yang baik keluar dari mereka dan hal-hal yang jahat masuk ke dalam mereka dan melalui celah itu ALLAH masuk untuk mengancurkannya. Ada cara untuk menutupi celah itu yaitu dengan pertobatan dan doa serta pembaharuan diri seperti Musa pada saat itu mengetengahi Amarah-Nya ALLAH dengan bersyafaat (Mzm. 106:23). ALLAH sebenarnya berharap ada seorang pemimpin-pemimpin Israel yang bersyafaat untuk kaum Israel, karena ALLAH mempunyai kerinduan yang besar dan kesukaan ALLAH untuk menunjukkan belas kasihan-Nya (Henry, 2018, p. 450). Namun tidak ada seorangpun dari pemimpin Israel yang dapat melakukan hal itu sehingga murka ALLAH dan penghakiman ALLAH atas kota Yerusalem tetap dilaksanakan.

Maka aku mencurahkan geram-Ku atas mereka dan membinasakan mereka dengan api kemurkaan-Ku. Menjadi pertanda buruk ketika suatu bangsa atau kota mendapat sebuah penghakiman ALLAH dan roh doa ditahan karena tidak akan ada seorangpun yang ditemui akan memberi perkataan baik kepada mereka ataupun berbicara perkataan baik demi mereka. ALLAH mencurahkan amarah-Nya dalam takaran penuh sehingga murka itu menimpa kaum Israel dalam aliran deras. Namun walaupun ALLAH menimpa murka-Nya sangat deras, ALLAH cuman menimpahkan kelakuan mereka atas kepalanya sebab ALLAH tidak menghajar mereka lebih dari itu (Henry, 2018, p. 450, 451). Itu sebabnya ALLAH membinasakan mereka karena kelakuan mereka yang najis dan kelakuan mereka yang melanggar segala peraturanperaturan yang telah ALLAH buat. Mulai dari pemimpin-pemimpin sampai kepada masyarakat atau kaum-kaum Israel semuanya melakukan kejahatan dan pelanggaran dan mereka menajiskan diri mereka dihadapan ALLAH itu sebabnya ALLAH ingin membinasakan mereka akibat perbuatan-perbuatan yang keji yang dilakukan orangorang di kota Yerusalem.

\section{Implikasi Praktis Yehezkiel 22:1-31}

ALLAH ingin menjatuhkan hukuman kepada kaum Israel di kota Yerusalem akibat dari hutang darah dan perbuatan keji yang mereka lakukan. Kaum Israel melakukan beberapa dosa-dosa yang ada di kota Yerusalem sehingga membuat kota Yerusalem penuh dengan dosa. ALLAH membuat putusan untuk menjatuhkan hukuman bagi kaum Israel atas dosa-dosa yang mereka perbuat. Tuduhan ALLAH terhadap dosa dan pelanggaran yang dilakukan nabi-nabi, imam-imam dan pemukapemuka di kota Yerusalem. Akibat dari dosa yang dilakukan oleh pemimpinpemimpin di kota Yerusalem membuat dampak negatif terhadap penduduk di kota Yerusalem sehingga ALLAH mencurahkan amarah-Nya atas mereka dan membinasakan mereka di kota Yerusalem. Pengaruh dari orang-orang yang berada di kota Yerusalem membuat kota Yerusalem di hancurkan oleh ALLAH. Dosa kota merupakan dosa yang dilakukan para pemimpin dan penduduk masyarakat. 


\section{Menjadi Teladan Dalam Memimpin}

Pemimpin-pemimpin di kota Yerusalem juga melakukan hal-hal yang melanggar hukum ALLAH, di mana mereka menindas dan merampas harta benda dan hak rakyatnya dengan membunuh, menindas, memeras, merampas dan berbohong atas nama ALLAH (ay. 7,25,26,27,28). Akibat dari dosa dan kesalahan yang dilakukan pemimpin-pemimpin Israel sehingga membuat ALLAH membinasakan mereka di tengah-tengah kota Yerusalem. Pemimpin-pemimpin di kota Yerusalem tidak memberikan sebuah teladan yang baik kepada masyarakat di kota Yerusalem sehingga mereka juga mengikuti apa yang dilakukan pemimpin-pemimpin. Pengaruh pemimpin di Yerusalem membuat kota itu menjadi binasa karena mereka sebagai pemimpin tidak taat kepada ALLAH.

Dalam kehidupan gereja masa kini seorang pemimpin sangat berpengaruh dalam perkembangan rohani sebuah jemaat dalam gereja. Sebagai seorang pemimpin sudah pasti harus menjadi teladan yang baik kepada orang-orang yang dipimpin. Itu sebabnya baik atau buruknya orang-orang yang dipimpin itu tergantung dari seorang pemimpin. Seorang pemimpin yang baik dan teladan harus memiliki suatu visi dan misi yang jelas. Sebagai seorang pemimpin Kristen dalam gereja harus mempunyai sebuah sikap yang perlu diperhatikan dalam motivasi kepemimpinan jabatan atau organisasi karena seorang pemimpin harus berhati-hati terhadap kesombongan. Ketika seorang pemimpin gereja mempunyai kesombongan dalam dirinya itu akan membuat dirinya menjadi angkuh. Sikap motivasi dari seorang yang menyombongkan diri atas kepemimpinannya dalam jabatan atau organisasi adalah bahwa mereka ingin mendapatkan pengakuan dari orang lain, ingin mendapatkan otoritas tertinggi, ingin menguasai dan mengendalikan orang lain dan ingin dihormati (Ronda, 2015, p. 65). Itu sebabnya sebagai pemimpin Kristen dalam gereja harus menjauhkan diri dari kesombongan karena itu bukanlah sebuah keteladan seorang pemimpin. Ketika seorang pemimpin menjadi sombong itu berarti dia memimpin untuk dirinya sendiri dan untuk mementingkan dirinya sendiri.

Kemudian seorang pemimpin gereja juga harus memiliki motivasi yang baik terhadap uang. Karena ketika seorang pemimpin gereja hanya terfokus terhadap uang saja pasti dia akan memperalat bawahan dan organisasinya untuk mencapai kekayaan dengan cara yang instan sehingga dia memimpin untuk mendapatkan uang saja (Ronda, 2015, p. 66). Di zaman masa kini banyak pemimpin-pemimpin yang memimpin hanya bertujuan agar dapat menjadi kaya dengan cara korupsi dan suap. Itu sebabnya pemimpin-pemimpin masa kini baik dalam sebuah jabatan atau organisasi banyak melakukan penindasan dan pemerasan terhadap bawahannya atau orang yang dipimpinnya dan juga akibat kekuasaan yang dimiliki pemimpinpemimpin masa kini, mereka bisa saja membunuh sesama manusia agar mendapatkan kekayaan yang instan.

Itu sebabnya sebagai pemimpin-pemimpin Kristen yang berada di dalam gereja harus menjadi teladan bagi orang yang dipimpin karena seorang pemimpin yang baik harus bersedia tunduk kepada ALLAH, tuduk kepada Firman TUHAN dan memiliki 
hati seperti Kristus agar dalam kepemimpinan di dalam gereja dapat membuat pengaruh yang baik terhadap sebuah kota dan terhindar dari dosa kota. Kota Yerusalem merupakan kota yang suci pada saat itu dan di zaman modern ini tidak ada kota yang suci lagi, itu sebabnya pengaruh pemimpin-pemimpin gereja untuk membangun rohani jemaat-jemaat agar dapat mempengaruhi sebuah kota.

\section{Menjauhkan Diri Dari Dosa yang Menajiskan}

Kaum Israel yang berada di kota Yerusalem mereka berbuat dosa yang manajiskan diri mereka (ay. 3) sehingga membuat ALLAH mencurahkan amarah-Nya atas mereka (ay. 21) padahal kaum Israel sudah mengetahui tentang peraturan dan ketetapan yang dibuat oleh $A L L A H$, namun mereka tidak taat kepada ALLAH dan terus berbuat dosa. Kota Yerusalem penuh dengan hutang darah akibat kaum Israel membuat dosa yang menajiskan. Itu sebabnya mereka semua najis di hadapan ALLAH karena dosa yang menajiskan mereka.

Pada hakikatnya dosa tidak bisa jauh dari diri manusia. Di mana kita sebagai manusia sudah dilahirkan dalam sifat dosa (Brill, 2015, p. 295). Kita berdosa karena dosa asal pada saat kejatuhan adam dan hawa di taman Firdaus (Mangis, 2011, p. 2). Dosa merupakan hal yang ada karena kesalahan dan pelanggaran yang dilakukan manusia. Itu sebabnya dalam sebuah kehidupan seseorang manusia tidak dapat memilih mana yang baik dan mana yang tidak baik karena hanya didalam Kristus manusia dapat memilih yang baik dan tidak baik. ALLAH telah memberikan peraturan-peraturan dan ketetapan dalam kehidupan manusia untuk diikuti agar manusia terhindar dan jauh dari dosa. Namun pada masa kini masih banyak manusia yang melakukan dosa dan melanggar ketetapan yang ALLAH berikan kepada manusia dan juga banyak manusia masa kini yang tidak taat akan peraturan yang diberikan ALLAH.

Sebagai orang percaya, hanya di dalam Kristus Yesus saja bisa membedakan hal yang baik dan yang buruk. Itu sebabnya sebagai orang percaya harus hidup telah jauh dari dosa yang menajiskan diri kita. Jadi sebagai orang percaya masa kini kita sudah diperdamaikan dengan ALLAH melalui pengorbanan Yesus di kayu Salib, kita harus tetap taat kepada ALLAH dan tetap menjahui dosa yang dapat menajiskan hidup, karena kehidupan kita sebagai orang percaya dapat memengaruhi juga orang lain dalam sebuah kota.

\section{Hidup Benar di Hadapan ALLAH}

Orang-orang di kota Yerusalem mereka hidup bertentangan dengan ajaran dan aturan yang ALLAH berikan di mana mereka melakukan kejahatan yang keji seperti pembunuhan, perampasan, penindasan, korupsi, pelecehan, ketidaktaatan kepada orang tua dan penyembahan berhala (ay. 3-12). Orang-orang yang di Yerusalem menjalani hidup dengan dosa, mereka tidak memperdulikan apa yang diajarkan ALLAH kepada mereka agar mereka hidup benar di hadapan ALLAH sehingga tidak membuat pengaruh jelek terhadap kota Yerusalem. 
Sebagai orang percaya masa kini pastinya kita harus hidup benar di hadapan ALLAH. Hidup benar di hadapan ALLAH artinya hidup mengikuti ajaran-ajaran dan aturan-aturan yang sudah ALLAH berikan kepada manusia. Ketika manusia melakukan setiap ajaran dan aturan yang ALLAH buat berarti dia menghormati hal itu dengan benar.

Jadi sebagai orang percaya masa kini harus memperlihatkan kehidupan yang benar seperti yang Yesus ajarkan yaitu tentang kasih karena jika dalam sebuah kehidupan bermasyarakat yang didasari dengan kasih maka setiap kejahatan atau dosa pasti tidak akan dilakukan.

\section{Membangun Hubungan yang Baik Dengan ALLAH}

Kaum Israel yang berada di kota Yerusalem, tidak melakukan hubungan baik dengan ALLAH sehingga mereka melakukan kejahatan dan perbuatan yang keji dengan cara menyembah berhala dan menajiskan hari sabat (ay. 4 dan 8). Mereka tidak menghormati hari-hari kudus yang menjadi hari untuk mereka manjalani hubungan dengan ALLAH. Mereka juga tidak memperdulikan keberadaan ALLAH dalam kehidupan mereka (ay. 12). Itu sebabnya ALLAH mencurahkan murka-Nya kepada mereka karena mereka telah menduakan ALLAH dan tidak menguduskan hari sabat.

Membangun hubungan yang baik dengan ALLAH adalah sesuatu yang bagus untuk kehidupan orang percaya karena membangun hubungan yang baik dengan ALLAH dapat membuat relasi semakin dekat. Sebagai orang percaya perlu melakukan hubungan baik dengan ALLAH agar dapat mengetahui maksud dan tujuan ALLAH dalam perjalanan hidup. Sebab perjalanan hidup seorang manusia semua telah diatur oleh ALLAH itu sebabnya perlu adanya hubungan yang baik atau relasi yang baik.

Di kota masa kini banyak orang percaya yang jarang melakukan hubungan yang baik dengan ALLAH, sebab mereka lebih membangun hubungan dengan dunia ini, mulai kesibukan, kekuasaan dan teknologi. Membangun sebuah hubungan yang baik dengan ALLAH dengan cara berdoa dan membaca Firman TUHAN. Karena ketika kita tidak melakukan hubungan yang baik dengan ALLAH maka kehidupan yang dijalani akan menjadi tersesat dan muda berbuat dosa serta kejahatan. Jadi sebagai orang percaya perlu adanya hubungan yang baik dengan ALLAH, agar kehidupan manusia jauh dari kejahatan dan dosa. Seperti dalam wahyu 2:5 dikatakan bahwa setiap jemaat dalam gereja jika tidak bertobat ALLAH akan mengambil kaki dian dari tempat mereka. Kaki dian merupakan sebuah tempat bagi sumber terang dan ALLAH adalah terang sehingga ketika ALLAH mengambil kaki dian tersebut dari tengah-tengah jemaat maka dalam sebuah kebaktian gereja didalamnya hanya pertemuan organisasi sosial (Hagelberg, 2005, p. 56) saja karena tidak ada ALLAH yang menjadi terang dalam gereja. Itu sebabnya harus membangun hubungan yang baik dengan ALLAH agar terang selalu ada di dalam gereja dan didalam hati orang-orang percaya. 


\section{KESIMPULAN}

Berdasarkan hasil uraian artikel ini mengenai dosa kota Yerusalem berdasarkan Yehezkiel 22:1-31 dan implikasinya bagi masyarakat kota masa kini, maka penulis dapat menarik kesimpulan sebagai berikut:

Pertama, ALLAH ingin menjatuhkan hukuman terhadap kaum Israel di kota Yerusalem akibat dari hutang darah dan perbuatan keji yang mereka lakukan. ALLAH di sini berperan sebagai hakim dan sebagai penuntut karena kaum Israel telah berbuat dosa dan kejahatan yang sangat melanggar hukum ALLAH. Dalam nubuatan ini seperti hal di dalam sebuah pengadilan di mana ALLAH ingin mengadili kaum Israel dan menjatuhkan hukum atas mereka.

Kedua, ALLAH menuntun segala perbuatan keji kaum Israel di kota Yerusalem mulai dari pemimpin-pemimpin sampai kepada rakyat biasa yang membuat kota itu banyak hutang darah. Mereka melakukan penyembahan berhala, pembunuhan, pemerasan, penindasan ketidaktaatan kepada orang tua dan menajiskan hari sabat serta hal-hal yang kudus. Akibat dari perbuat kaum Israel yang keji ini membuat ALLAH mencurahkan api amarah-Nya kepada kaum Israel di kota Yerusalem. ALLAH menganggap kaum Israel seperti sanga atau kotaran dari sebuah logam yang tidak ada gunanya lagi dan sudah tidak bisa dimurnikan, itu sebabnya ALLAH ingin meleburkan mereka dengan api amarah-Nya sampai tidak tersisa.

Ketiga, ALLAH membinasakan kota Yerusalem karena akibat dari pemimpinpemimpin di kota Yerusalem berbuat pelanggaran dan kejahatan yang melanggar ketetapan-ketetapan ALLAH. Pemimpin-pemimpin di kota Yerusalem masih mengikuti cara hidup nenek moyang mereka yang suka memberontak terhadap ALLAH dan juga mereka masih mengandalkan penyembahan berhala serta mempercayai dewa-dewa. Masyarakat di kota Yerusalem berbuat dosa karena mereka melihat pemimpin-pemimpin mereka berbuat hal demikian sehingga mereka berbuat kejahatan satu sama lain di tengah-tengah kota Yerusalem. Sebenarnya ALLAH mencari seorang pemimpin yang hidup benar di hadapan ALLAH, tapi ALLAH tidak menemukannya karena satu kota Yerusalem semua berbuat kejahatan dan dosa, oleh sebab itu ALLAH akan membinasakan kota Yerusalem berserta kaum Israel akibat kejahatan mereka yang keji.

\section{KEPUSTAKAAN}

Achenbach, R. (2012). Kamus Ibrani-Indonesia: Perjanjian Lama (Edisi 1). Jakarta: Yayasan Komunikasi Bina Kasih.

Andrew E. Hill, \& J. H. Walton. (2013). Survei Perjanjian Lama. Malang: Gandum Mas. Brill, J. W. (2015). Dasar Yang Teguh. Bandung: Kalam Hidup.

Gemeran, W. A. V. (2011). Penginterpretasian Kitab Para Nabi. Surabaya: Momentum. 
Gertz, J. C., A. Berlejung, K. Schmid, \& M. Witte. (2017). Purwa Pustaka Eksplorasi ke dalam kitab-kitab Perjanjian Lama dan Deuterokanonika. Jakarta: BPK Gunung Mulia.

Guthrie, Donald, dkk. (2000). Tafsiran Alkitab Masa Kini 1 Kejadian-Ester. Jakarta: Yayasan Komunikasi Bina Kasih.

Hagelberg, D. (2005). Tafsiran Kitab Wahyu dari Bahasa Yunani (Revisi). Yogyakarta: ANDI (Anggota IKAPI).

Henry, M. (2018). Tafsiran Matthew Henry Kitab Yehezkiel. Surabaya: Momentum.

Mangis, M. (2011). Dosa Ciri Diri Menjinakkan kecenderungan Liar Hati Kita. Tuban: Waskita Publishing.

Odell, M. S. (2005). Ezekiel. Grand Rapids, Mich.: Smyth \& Helwys Pub.

Paat, S. F. Y. (2016). Komplemen Dalam Kitab Yehezkiel (Suatu Analisis Sintaksis). Jurnal Elektronik Fakultas Sastra Universitas Sam Ratulangi, 3(2). https://ejournal.unsrat.ac.id/index.php/jefs/article/view/12890.

Ronda, Daniel. (2015). Leadership Wisdom Antologi Hikmat Kepemimpinan. Bandung: Kalam Hidup.

Sutanto, Hasan. (2007). Hermeneutik: Prinsip dan Metode Penafsiran. Malang: Literatur SAAT.

Tarigan, I. S. (2020). Teologi Dosa Dalam Kitab Ratapan. JURNAL PIONIR, 7(3), $106-$

111. http://jurnal.una.ac.id/index.php/pionir/article/download/1379/1149.

Tuell, S. S. (2009). Ezekiel: Old Testament Series New International Biblical Commentary. USA: Hendrickson Publishers, Inc.

Walvoord, J. F. (2003). Pedoman Lengkap Nubuat Alkitab. Bandung: Kalam Hidup.

Wevers, J. W. (1982). Ezekiel (Softback ed). Grand Rapids, Mich.: Eerdmans Publishing.

Wijaya, Hengki. (2016). Metodologi Penelitian Pendidikan Teologi. Makassar: Sekolah Tinggi Theologia Jaffray. 